\title{
METATARSAL LENGTHENING BY CALLOTASIS DURING THE GROWTH PHASE
}

\author{
B. MAGNAN, A. BRAGANTINI, D. REGIS, P. BARTOLOZZI
}

From the University of Verona, Italy

Congenital or acquired shortness of a metatarsal may cause pain in adjacent metatarsals. From 1983 to 1990, we performed nine metatarsal lengthenings in seven adolescent patients by metaphyseal osteotomy followed by gradual distraction of callus (callotasis). Two patients required bone grafts after the lengthening.

We used a rigid, unilateral external fixator designed for use in the hand and foot. At follow-up, from three to ten years later, healing had been achieved in all with an average healing index of $50 \mathrm{days} / \mathrm{cm}$, and metatarsalgia had been relieved by the restoration of correct metatarsal length.

J Bone Joint Surg [Br] 1995;77-B:602-7.

Received 11 August 1994; Accepted 5 October 1994

Metatarsalgia is common when there is functional or anatomical shortening of one or more metatarsals. The aetiology may be congenital or acquired after Freiberg's disease, trauma or iatrogenic damage.

Congenital metatarsal shortening (brachymetatarsia) is sometimes hereditary and may be unilateral or bilateral (McGlamry and Cooper 1969; McGlamry and Fenton 1983). It is normally idiopathic, but can be a marker of pseudohypoparathyroidism or Turner's syndrome. It is usually symptomless, but may cause pain in the adjacent metatarsals which may be severe. This results from mechanical insufficiency of the short metatarsal, and the associated axial deviation or claw-toe deformity can cause problems on walking.

The fourth metatarsal is most often affected, with early closure of the epiphyseal plate. Surgical correction is indicated for symptoms or when the appearance is unacceptable to the patient, but commonly no treatment is necessary.

B. Magnan, MD, First Assistant

A. Bragantini, MD, Assistant

D. Regis, MD, Assistant

P. Bartolozzi, MD, Head of Orthopaedic Department

Ospedale Policlinico, Istituto di Clinica Ortopedica e Traumatologica,

Università degli Studi di Verona, 37134 Verona, Italy.

Correspondence should be sent to Dr B. Magnan.

C1995 British Editorial Society of Bone and Joint Surgery

0301-620X/95/4979\$2.00
Lengthening the short bone is the most logical treatment, with the aim of restoring the normal length of the metatarsal according to the formula $1=2>3>4>5$ (Lelièvre 1971).

Major surgery is not required, but a number of minor procedures have been reported. These include osteotomy with immediate angular correction and bone grafting (Lelièvre 1971; Kaplan and Kaplan 1978; Pisani and Andreasi 1982) osteotomy without bone grafting (Lorenzi et al 1983; Mori et al 1983), osteotomy followed by gradual distraction and the application of a bone graft (Walter and Pressman 1981; Urbaniak and Richardson 1985; Magnan and Nogarin 1986) or without grafting (Skirving and Newman 1983; Nogarin et al 1988; Saxby and Nunley 1992), and epiphyseal distraction using the chondrodiatasis technique (Nogarin et al 1988).

The use of an external fixator for gradual metatarsal elongation was first reported by Skirving and Newman (1983); fixators designed specifically for use in the hand and foot have subsequently become available. Some are rigid, monoaxial devices for lengthening alone, while others incorporate articulated clamps to allow additional angular corrections. The techniques are now well established (Ilizarov, Deviatov and Trokhovva 1972; Magnan and Nogarin 1986; Nogarin et al 1988; Saxby and Nunley 1992).

\section{PATIENTS AND METHODS}

From 1983 to 1990 , we performed nine metatarsal lengthenings in four girls and three boys with an age range of 8 to 19 years at the Institute of Orthopaedics and Traumatology of the University of Verona. The metatarsal shortening was congenital in five patients, secondary to congenital club foot in one, and post-traumatic in one. Two of the congenital cases required the correction of two segments: unilateral lengthening of the third and fourth metatarsals in one patient and bilateral lengthening of the fourth metatarsal in the other. In both, each segment was lengthened separately.

We used metaphyseal osteotomy with gradual distraction at $1 \mathrm{~mm}$ per day. Autologous bone graft from the ipsilateral iliac crest was added in two cases and gradual distraction by callotasis from the seventh postoperative day was used without bone grafting in seven. With the latter technique, the rate of distraction should not exceed $1 \mathrm{~mm}$ per day. 


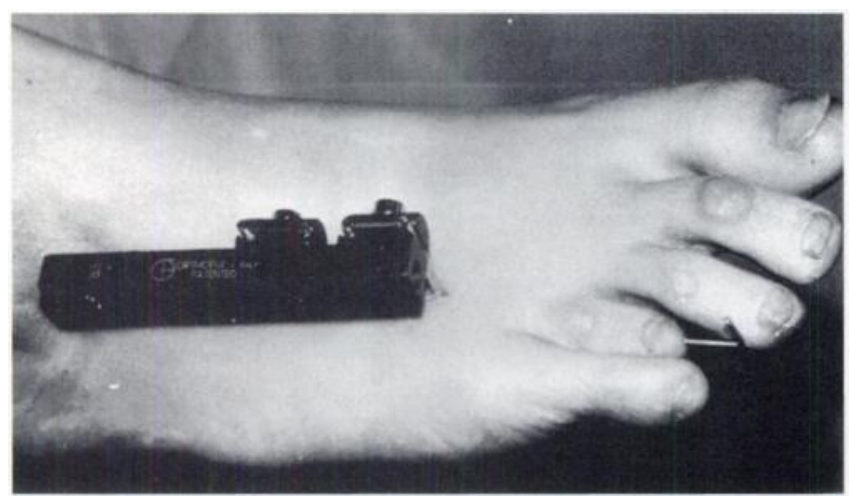

Fig. 1

Use of a rigid minifixator frame for metatarsal lengthening both for cases treated with a bone graft and those treated by the callotasis alone.

The lengthenings were performed using a rigid rail fixator specifically designed for foot surgery (Mini-DAF; Orthofix srl, Verona, Italy; Fig. 1), and self-drilling, selftapping screws with $3 \mathrm{~mm}$ diameter shafts and $3 \mathrm{~mm} /$ $2.5 \mathrm{~mm}$ tapered threads. The frame is unilateral, with two proximal and two distal screws placed on the dorsal aspect.

Lengthening was carried out exactly in line with the long axis of the bone. Excessive plantar deviation can lead to pain in the lengthened metatarsal, while dorsal deviation may fail to relieve pain in the adjacent segments. Lateral or medial deviation may cause painful contact between metatarsal heads, with the development of bursitis or degenerative osteochondritis. It is also essential to maintain metatarsophalangeal and interphalangeal alignment to prevent iatrogenic subluxation and axial deviation. In six cases we achieved this alignment by the introduction of a Kirschner wire to the level of the metatarsal head with an accessory clamp distally in one case. Weight-bearing started gradually during the final stages of healing before the fixator was removed; the latter was left in place for 20 to 30 days after weight-bearing had begun. Details of each patient are shown in Table $\mathrm{I}$.

Assessment at the end of treatment included the length achieved in absolute terms and as a percentage of the original length, the healing time in days and the healing index (HI), defined as the ratio between the healing time in days and the lengthening achieved in centimetres. Complications were classified as benign, serious or severe, according to Caton et al (1985), and were further classified as mechanical, biological or functional (Table II).

Follow-up ranged from 3 to 10 years (mean 6.5). Radiological assessment at follow-up included the measurement of any axial deviation, the restoration of a correct metatarsal formula and the extent of any residual discrepancy. Clinical assessment included the recording of any residual metatarsalgia, the gait, and the need for any specific modifications to footwear.

\section{RESULTS}

The lengthened segment consolidated in all cases. The lengthening achieved, the healing time and the $\mathrm{HI}$ are shown in Table III; the mean HI was 50 days per centimetre gained.

Complications are detailed in Table IV. One superficial pin-track infection resolved in two weeks with local antibiotics (case 6) and did not require cessation of distraction. In case 3, treated for extreme shortness of the third metatarsal, there was irreducible dislocation of the metatarsophalangeal joint after removal of the accessory clamp used for stabilisation. An 8-year-old patient (case 7) had early fusion of the osteotomy because of delay in starting distraction, and required a second operation to reopen the osteotomy.

Table I. Details of patients and lengthening techniques

\begin{tabular}{lllllllll}
\hline Case & $\begin{array}{l}\text { Age } \\
\text { (yr) }\end{array}$ & Sex & Segment & Side & Aetiology & Metatarsalgia & $\begin{array}{l}\text { Lengthening } \\
\text { technique }\end{array}$ & $\begin{array}{l}\text { Method of MTP* } \\
\text { stabilisation }\end{array}$ \\
\hline 1 & 17 & M & 2 & R & Congenital & 1.3 & $\begin{array}{l}\text { Gradual distraction } \\
\text { + autologous graft }\end{array}$ & - \\
2 & 19 & M & 2 & L & $\begin{array}{l}\text { Post-traumatic } \\
\text { (nonunion) }\end{array}$ & 1 & $\begin{array}{l}\text { Gradual distraction } \\
\text { + autologous graft }\end{array}$ & - \\
3 & 17 & F & 3 & R & $\begin{array}{l}\text { Congenital } \\
\text { Congenital }\end{array}$ & 2.5 & $\begin{array}{l}\text { Callotasis } \\
\text { Callotasis }\end{array}$ & $\begin{array}{l}\text { Accessory clamp } \\
\text { K-wire }\end{array}$ \\
4 & 15 & F & 4 & L & Congenital & 4 & Callotasis & K-wire \\
5 & 13 & F & 4 & L & Congenital & 3.5 & Callotasis & K-wire \\
6 & 14 & F & 4 & R & $\begin{array}{l}\text { Congenital } \\
\text { Congenital }\end{array}$ & - & Callotasis & K-wire \\
Callotasis & K-wire \\
7 & 8 & M & 1 & L & Club-foot & 2.3 & Callotasis & K-wire \\
\hline
\end{tabular}

* metatarsophalangeal 


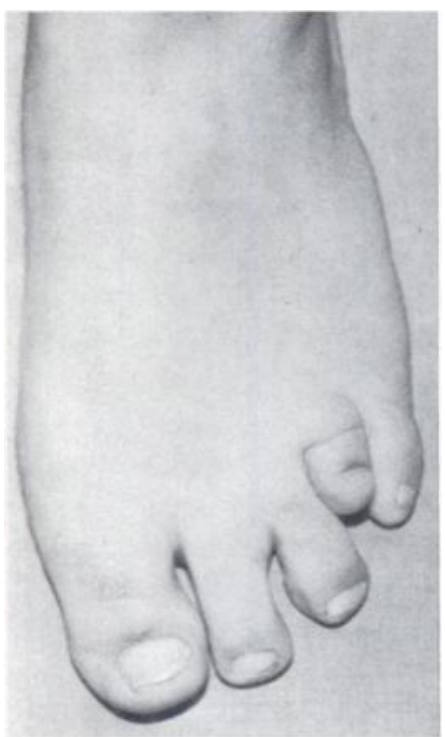

Fig. 2a

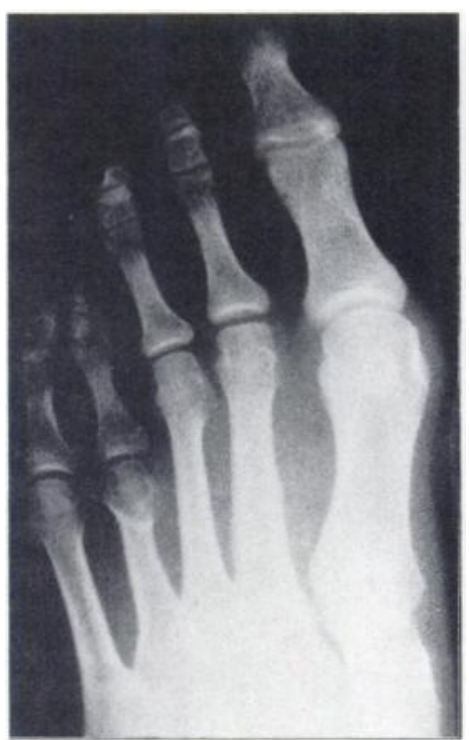

Fig. 2b

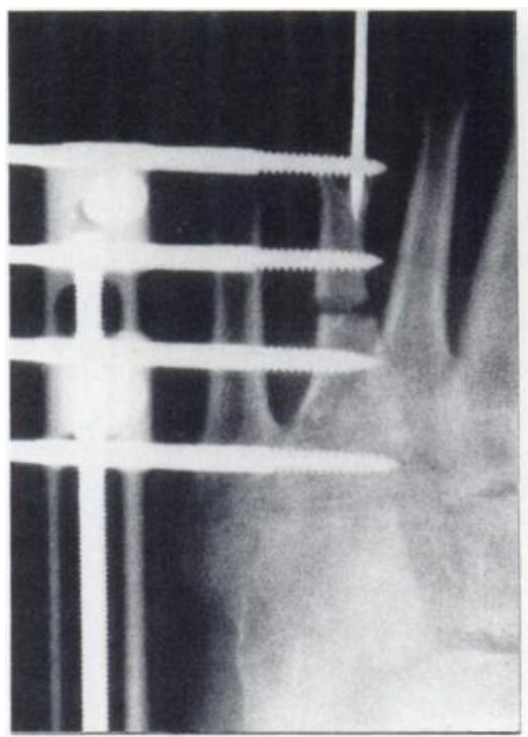

Fig. 2c

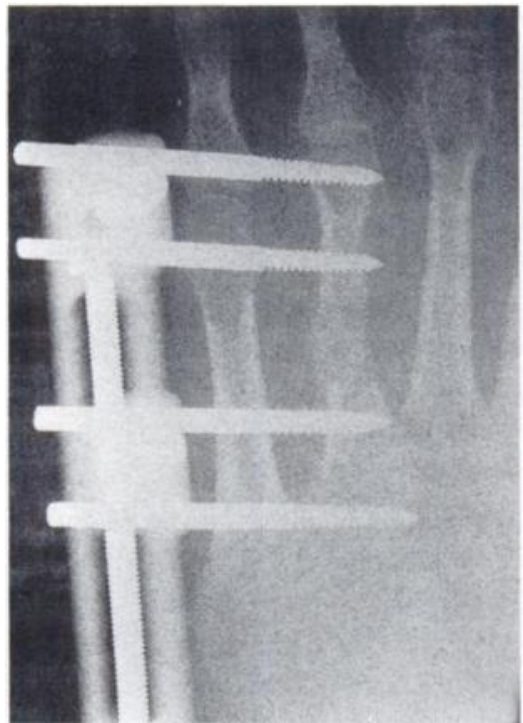

Fig. 2d

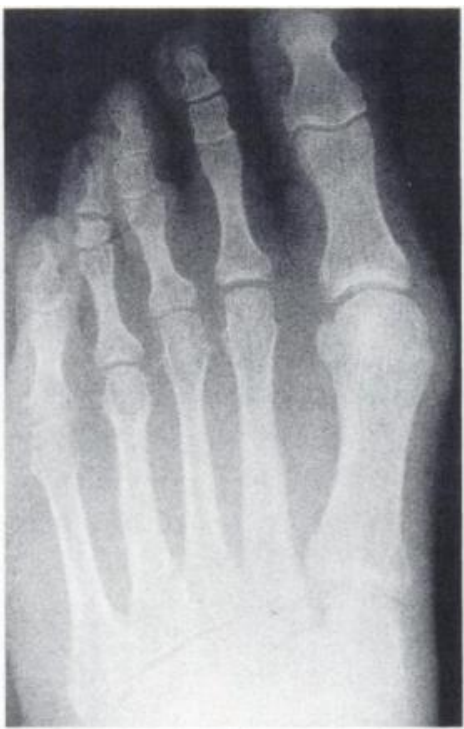

Fig. 2e

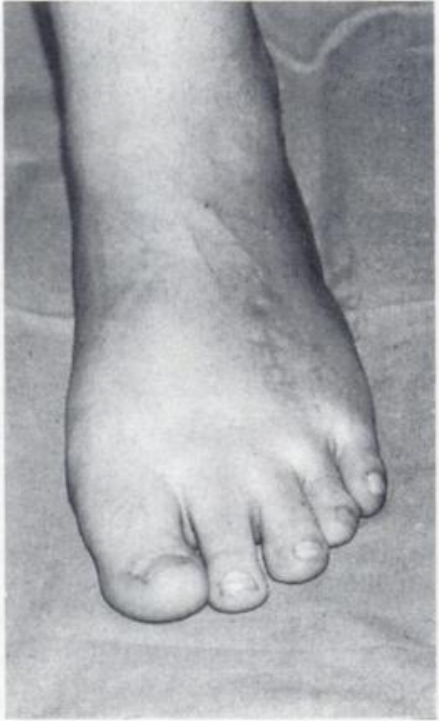

Fig. 2f

Congenital shortening of the fourth metatarsal in a patient aged 14 years. Preoperative clinical appearance, with pain in the third and fifth metatarsals (a). Preoperative radiograph (b). Radiographs at the start of distraction (c), during consolidation (d) and at six-year follow-up (e). Lengthening of $15 \mathrm{~mm}$ was achieved $(=30 \%$ of original length). Clinical appearance at follow-up (six years) (f).

Table II. Classification of complications during lengthening

\begin{tabular}{ll}
\hline Complication & \\
\hline Benign & $\begin{array}{l}\text { Does not jeopardise result } \\
\text { Does not increase HI } \\
\text { Treated without anaesthesia }\end{array}$ \\
Serious & $\begin{array}{l}\text { Does not jeopardise result or course of treatment } \\
\text { May delay HI } \\
\text { Treated under anaesthesia }\end{array}$ \\
Severe & $\begin{array}{l}\text { Jeopardises result } \\
\text { Stops lengthening } \\
\text { Stops course of treatment }\end{array}$ \\
\hline
\end{tabular}

The long-term radiological findings are shown in Table V. Figure 2 illustrates a typical result (case 6). The correct metatarsal formula was achieved in seven of the nine lengthenings, but was subsequently lost in one. In this patient (case 7), six-year follow-up showed that the lengthened first metatarsal had grown less than the adjacent metatarsals, and this had resulted in a $17 \mathrm{~mm}$ deficit. In case 3, complicated by metatarsophalangeal dislocation, the correct metatarsal formula was never achieved. Axial deviation was found in only one patient (case 5) who had a varus deformity.

Clinical assessment confirmed the absence of metatarsal- 


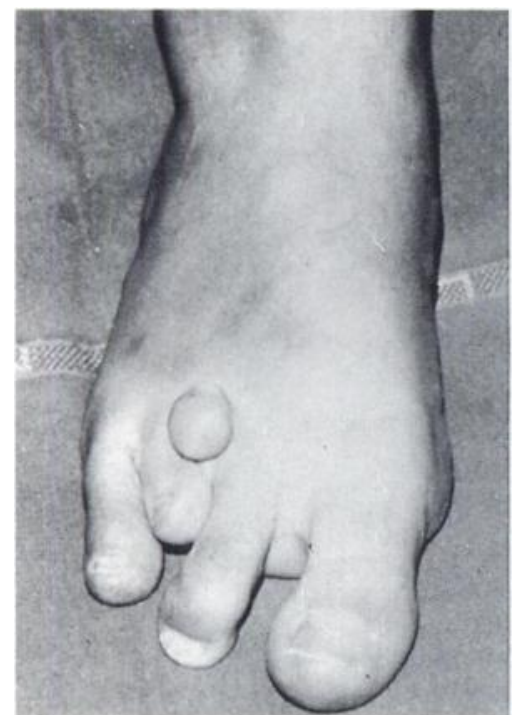

Fig. 3a

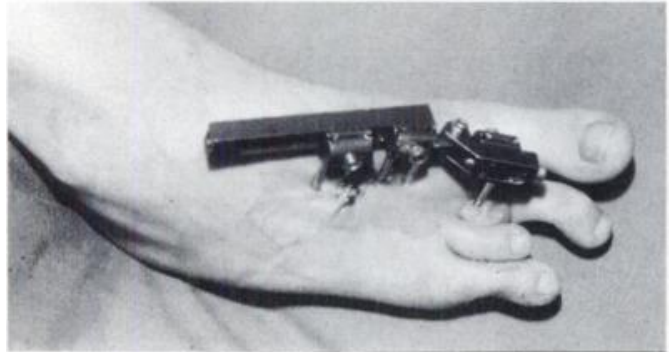

Fig. 3d

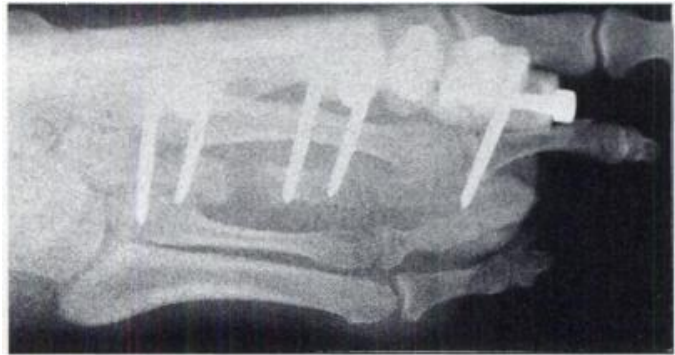

Fig. 3e

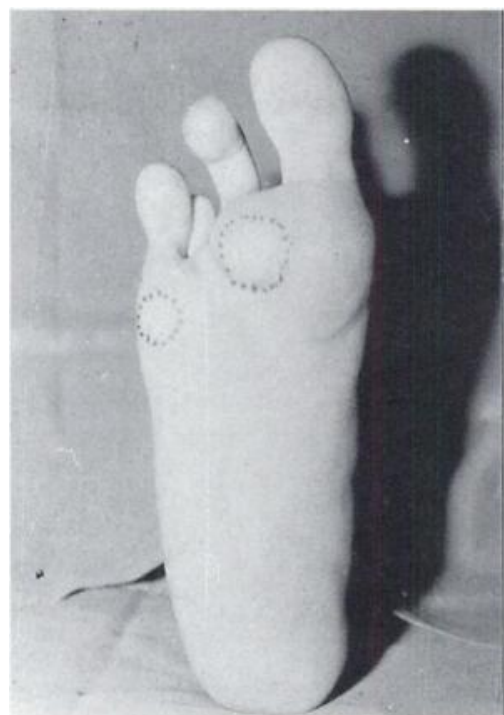

Fig. 3b

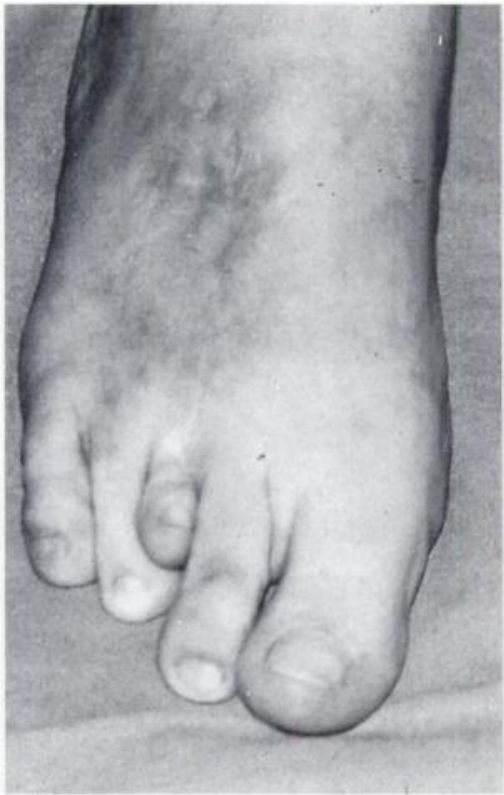

Fig. 3f

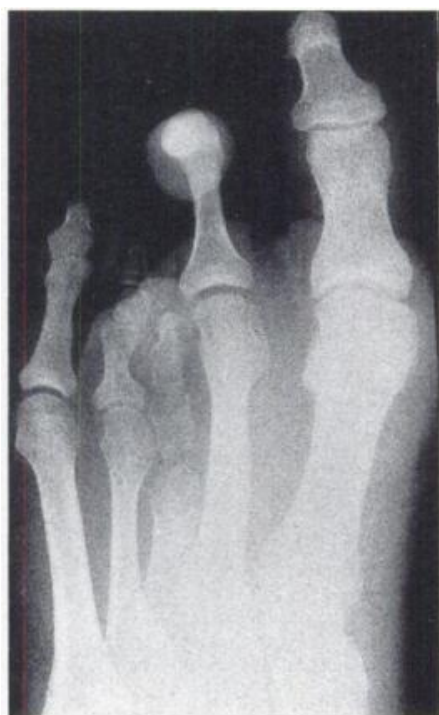

Fig. 3c

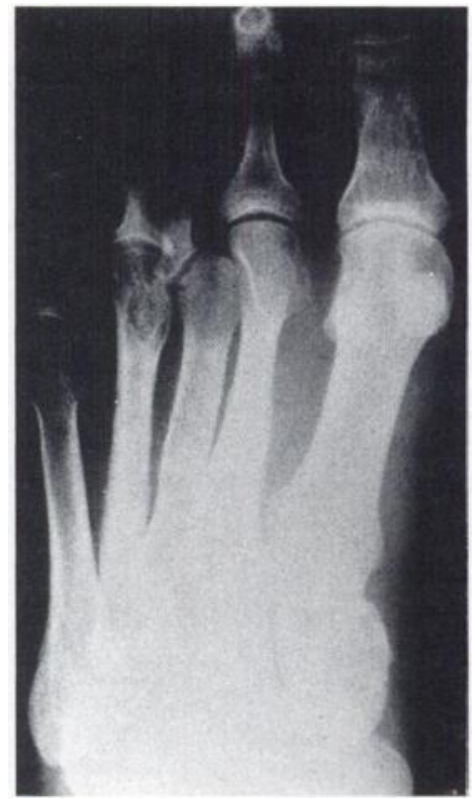

Fig. 3g

Congenital shortening of the third and fourth metatarsals in a patient aged 17 years. Lengthening by callotasis was $26 \mathrm{~mm}(65 \%)$ and $15 \mathrm{~mm}(24 \%)$ respectively. The two segments were not treated simultaneously. Figures $3 \mathrm{a}$ and $3 \mathrm{~b}-$ Preoperatively, there was pain at the second and fifth metatarsal loads. Figure 3c - Preoperative radiograph. Figures 3d and 3e - During distraction of the third metatarsal, showing the accessory clamp used for stabilisation. Figures $3 \mathrm{f}$ and $3 \mathrm{~g}$ - At seven years there is a satisfactory appearance, despite dislocation of the third metatarsophalangeal joint and a painful fourth metatarsal head. This is $5 \mathrm{~mm}$ longer than dictated by the metatarsal formula.

gia in all but the single patient (case 3) with dislocation of one joint. In this patient, however, the pain was only in the fourth metatarsal; the preoperative pain in the second and fifth metatarsals had been relieved (Fig. 3). No patient required an orthosis or special footwear of any kind and all had a normal gait.

\section{DISCUSSION}

Our experience confirms other reports on the pathogenesis of the congenitally short metatarsal (Mori et al 1983), which suggest that it is caused by premature fusion of the distal growth plate.

The results from our small study show that metatarsal lengthening is an acceptable treatment for the symptomatic short metatarsals. When lengthening did not exceed $50 \%$ of the original length we had no serious or severe complications and clinical follow-up was completely satisfactory. Callotasis involves the distraction of newly-formed callus, and has been shown to be reliable and safe provided that 
Table III. Length achieved, healing time and healing index (HI) in seven patients

\begin{tabular}{lllllll}
\hline Case & $\begin{array}{l}\text { Age } \\
(\mathbf{y r})\end{array}$ & Segment & $\begin{array}{l}\text { Lengthening } \\
(\mathbf{m m})\end{array}$ & $\begin{array}{l}\text { \% Original } \\
\text { length }\end{array}$ & $\begin{array}{l}\text { Healing time } \\
\text { (days) }\end{array}$ & HI (days/cm) \\
\hline 1 & 17 & 2 & 18 & 25 & 90 & 50 \\
2 & 19 & 2 & 20 & 36.3 & 120 & 60 \\
3 & 17 & 3 & 26 & 65 & 150 & 57 \\
& & 4 & 15 & 24.1 & 120 & 80 \\
4 & 15 & 4 & 20 & 52.6 & 120 & 45 \\
5 & 13 & 4 & 15 & 30 & 75 & 50 \\
6 & 14 & 4 & 27 & 62.7 & 100 & 37 \\
& & & 20 & 40 & 80 & 40 \\
7 & 8 & 1 & 40 & 83.3 & 140 & 35 \\
\hline
\end{tabular}

Table IV. Details of complications

\begin{tabular}{llll}
\hline & Complications & & \\
\cline { 2 - 4 } Case & Benign & Serious & Severe \\
\hline 3 & - & - & $\begin{array}{l}\text { Dislocation third } \\
\text { MTP joint* }\end{array}$ \\
6 & $\begin{array}{l}\text { Superficial } \\
\text { pin-track infection }{ }^{\dagger}\end{array}$ & - & - \\
7 & - & $\begin{array}{l}\text { Early fusion }{ }^{*} \\
\text { (osteotomy reopened) } \\
\text { Varus MTP joint* }\end{array}$ \\
\hline
\end{tabular}

* mechanical problem

† biological problem

the fixation used is capable of providing satisfactory purchase and stability. The minifixator which we used fulfilled these requirements, and our experience suggests that callotasis is safer and less traumatic than techniques which involve bone grafting at the end of the distraction period, and does not increase healing time. The restoration of the correct metatarsal formula was always associated with the disappearance of metatarsalgia.

As for any lengthening procedure, callotasis of the metatarsal requires careful monitoring of progress throughout distraction and consolidation. Restoration of the correct metatarsal proportions requires exact control of the amount of distraction and scrupulous attention to local factors to prevent complications. The most serious complication in our series was metatarsophalangeal dislocation in a patient with extreme shortness of the third metatarsal and articular

\section{REFERENCES}

Caton J, Dumont P, Berard J, Michel CR. Etude des résultats à moyen terme d'une série de 33 allongements des membres inférieurs selon la technique de H. Wagner. Rev Chir Orthop 1985;71:44-8.

Ilizarov GA, Deviatov AA, Trokhovva VG. Surgical lengthening of the shortened lower extremity. Vestn Khir 1972;1:100-13.
Table V. Long-term radiological findings in seven patients

\begin{tabular}{lllll}
\hline Case & Segment & $\begin{array}{l}\text { Follow-up } \\
\text { (yr) }\end{array}$ & $\begin{array}{l}\text { Axial } \\
\text { deviations }\end{array}$ & $\begin{array}{l}\text { Difference } \\
\text { from MT formula }\end{array}$ \\
\hline 1 & 2 & 10 & - & None \\
2 & 2 & 10 & - & None \\
3 & 3 & 7 & - & $-2 \mathrm{~mm}$ \\
& 4 & 7 & - & $+5 \mathrm{~mm}$ \\
4 & 4 & 7 & - & None \\
5 & 4 & 6 & Varus $6^{\circ}$ & None \\
& 4 & 3 & - & None \\
6 & 4 & 3 & - & None \\
& 4 & 6 & - & $-17 \mathrm{~mm}$ \\
7 & 1 & & & \\
\hline
\end{tabular}

dysplasia. The temporary use of a Kirschner wire during distraction is therefore indicated even for minor degrees of lengthening, particularly when, as in our series, the operation does not include tendon lengthening or capsuloplasty.

In our series, the increased metatarsal length was well maintained in all but one patient who had been treated at the age of eight years. All the other patients had been treated at the age of 13 years or more, shortly before fusion of the metatarsal epiphyses, which usually occurs between the ages of 14 and 21 years (Tachdjian 1972).

No benefits in any form have been received or will be received from a commercial party related directly or indirectly to the subject of this article.

Kaplan EG, Kaplan GS. Metatarsal lengthening by use of autogenous bone graft and internal wire compression fixation: a preliminary report. J Foot Surg 1978;17:60-6.

Lelièvre J. Pathologie du pied. Paris, Masson 1971. 
Lorenzi GL, Dettoni A, Quaglia F, Peveraro A. Biomechanical and technical aspects of two-layer metatarsal realignment techniques. Chir Piede 1983;7:131-6.

Magnan B, Nogarin L. Surgical elongation of metatarsal bones in different pathologies. Actual Med Chir du Pied 1986;16:210-3.

McGlamry ED, Cooper CT. Brachymetatarsia: a surgical treatment. J Am Podiatry Assoc 1969;59:259-64.

McGlamry DE, Fenton CF III. Brachymetatarsia: a case report. J Am Podiatry Assoc 1983;73:75-8.

Mori F, Molfetta L, Sgura A, Patella V. Congenital shortness of the 4th metatarsal. Chir Piede 1983;7:37-44.

Nogarin L, Magnan B, Bragantini A, Molinaroli F. Allungamento ed accorciamento diafisario nelle dismetrie metatarsali. GIOT 1988;14:79-82.
Pisani G, Andreasi A. Osteotomie e resezioni metatarsee. Chir Piede $1982 ; 1: 30-1$.

Saxby T, Nunley JA. Metatarsal lengthening by distraction osteogenesis: a report of two cases. Foot and Ankle 1992;13:536-9.

Skirving AP, Newman JH. Elongation of the first metatarsal. $J$ Pediatr Orthop 1983;3:508-10.

Tachdjian MO. Pediatric Orthopaedics. Philadelphia, etc;WB Saunders Company, 1972.

Urbaniak JR, Richardson WJ. Diaphyseal lengthening for shortness of the toe. Foot and Ankle 1985;5:251-6.

Walter JH, Pressman MM. External fixation in the treatment of metatarsal nonunions. J Am Podiatry Assoc 1981;71:297-301. 